\title{
Sex-specific differences in the dynamics of cocaine- and amphetamine-regulated transcript and nesfatin-1 expressions in the midbrain of depressed suicide victims vs. controls
}

\author{
Bernard Bloem $^{\mathrm{a}, 1}$, Lu Xu $^{\mathrm{a}, 1}$, Éva Morava ${ }^{\mathrm{b}}$, Gábor Faludi ${ }^{\mathrm{c}}$, Miklós Palkovits ${ }^{\mathrm{d}}$, \\ Eric W. Roubos ${ }^{a}$, Tamás Kozicz ${ }^{\mathrm{a}, *}$ \\ ${ }^{a}$ Department of Cellular Animal Physiology, Donders Institute for Brain, Cognition and Behaviour, Radboud University Nijmegen, 6525 AJ Nijmegen, The Netherlands \\ ${ }^{\mathrm{b}}$ Department of Pediatrics, Radboud University Medical Centre Nijmegen, 6500 HB Nijmegen, The Netherlands \\ ${ }^{\mathrm{c}}$ Department of Clinical and Theoretical Mental Health, Semmelweis University, Budapest, Hungary \\ ${ }^{\mathrm{d}}$ Neuromorphological and Neuroendocrine Research Laboratory, Hungarian Academy of Sciences and Semmelweis University, Budapest, Hungary
}

\section{A R T I C L E I N F O}

\section{Article history:}

Received 18 May 2011

Received in revised form

11 July 2011

Accepted 13 July 2011

\section{Keywords:}

Nesfatin-1

Nucleobindin 2

Major depressive disorder

Suicide

Edinger-Westphal nucleus

Q-RT-PCR

Short post-mortem time

\begin{abstract}
A B S T R A C T
An intriguing novel pathophysiological insight into mood disorders is the notion that one's metabolic status influences mood. In rodents, cocaine- and amphetamine-regulated transcript (CART) and nesfatin$1 /$ NUCB2 have not only been implicated in metabolism, but in the pathobiology of anxiety and depressive-like behaviour, however they have not previously been investigated in depressed subjects. Both peptides are highly expressed in centrally projecting neurons in the Edinger-Westphal nucleus (EWcp) in the midbrain. The EWcp has been implicated in stress adaptation and stress-related mood disorders like major depressive disorder in a sex-specific manner. This is intriguing, given the fact that females have higher prevalence of mood disorders. Here, we hypothesized that the expression of CART and nesfatin-1 in EWcp would exhibit a sex-specific difference between depressed suicide victims $v$. controls. We found that CART and nesfatin/NUCB2 colocalized in the human EWcp, and that CART mRNA content was much higher in both male $(\times 3.8)$ and female $(\times 5.9)$ drug-free suicide victims than in controls (persons who died without any diagnosed neurodegenerative or psychiatric disorder). Similarly, NUCB2 mRNA content was also higher $(\times 1.8)$ in male suicides, whereas in female suicide victims, these contents were $\times 2.7$ lower compared to controls. These observations are the first to show changes in the dynamics of CART and nesfatin/NUCB2 expressions in the midbrain of drug-free depressed suicide victims vs. controls.

This article is part of a Special Issue entitled 'Anxiety and Depression'.
\end{abstract}

( 2011 Elsevier Ltd. All rights reserved.

\section{Introduction}

Unravelling the pathobiology of major depressive disorder (MDD) is a major challenge. Recently significant interest has arisen in possible interactions between central mood substrates and circuitries involved in metabolism (Gomez-Pinilla, 2008; Krishnan and Nestler, 2008; Kuperman et al., 2010; McBriar, 2006; Shao et al., 2008). More specifically, several neuropeptides with a clear role in metabolism, such as leptin, ghrelin, orexin, neuropeptide Yand urocortin 3, produce clear anti-depressant-like responses (Eaton et al., 2007; Heilig, 2004; Kuperman et al., 2010; Lu, 2007; Lutter et al., 2008; Yamada et al.,

\footnotetext{
* Corresponding author. Tel.: +31243652554; fax: +31243652714 .

E-mail address: t.kozicz@science.ru.nl (T. Kozicz).

1 These two authors contributed equally to this work.
}

2011), whereas e.g. melanin-concentrating hormone and cholecystokinin evoke a pro-depressant-like phenotype in several rodent models (Becker et al., 2008; Georgescu et al., 2005).

To further support this notion, we have focused in the present study on two neuropeptides implicated in energy metabolism, viz. cocaine- and amphetamine-regulated transcript peptide (CART; (Douglass et al., 1995) and the recently identified nesfatin-1 (Oh et al., 2006). The highest expression of CART and nesfatin-1 in rodents is in centrally projecting neurons in the midbrain EdingerWestphal nucleus (EWcp; Brailoiu et al., 2007; Couceyro et al., 1997; Koylu et al., 1998; Kozicz, 2003; Kozicz et al., 2011a). The EW has originally been identified as the source of the preganglionic parasympathetic outflow to the ciliary ganglion (Edinger, 1885; Westphal, 1887) with preganglionic autonomic neurons exhibiting choline acetyltransferase (ChAT) immunoreactivity (Kozicz et al., 2011a). However, the discovery of a distinct population of 
neurons that do not colocalize with ChAT immunoreactivity, and produce urocortin-1, CART and nesfatin-1 (Brailoiu et al., 2007; Foo et al., 2008; Koylu et al., 1998; Kozicz et al., 1998, 2011a; Vaughan et al., 1995; Xu et al., 2010), neuropeptides tied to the stress response and stress-related mood disorders such as depression, has markedly extended our insight into the functional significance of this midbrain nucleus (for reviews see: Garcia-Galiano et al., 2010; Gysling et al., 2004; Kozicz, 2007; Kozicz et al., 2011b; Pan and Kastin, 2008; Rogge et al., 2008; Skelton et al., 2000).

The possible significance of CART in stress-related psychopathologies derives from the facts that a) CART mRNA is downregulated in the frontal cortex of rats subjected to a chronic mildstress (Orsetti et al., 2008); b) CART-immunoreactivity is increased in the periaqueductal grey in a genetic rat model for depression (Flinders-Sensitive-Line-FSL; (Wiehager et al., 2009); and c) CARTimmunoreactivity is reduced in various brain areas of socially isolated and olfactory bulbectomized rats (Dandekar et al., 2008). Furthermore, a study of an Italian family with high levels of anxiety and MDD has indicated an association between these disorders and a point mutation in the CART gene (Miraglia del Giudice et al., 2006).

Nesfatin-1 is a product of the NEFA/nucleobindin 2 (NUCB2) gene, and was recently identified as a potent satiety agent (Oh et al., 2006). NUCB2 is a precursor protein that is cleaved by prohormone convertases into multiple fragments with largely unknown biological functions (Foo et al., 2008; Oh et al., 2006). Upon intracerebroventricular administration, nesfatin-1 exerts, besides a strong anorexigenic action, anxiogenic effects as well (Garcia-Galiano et al., 2010; Merali et al., 2008). Interestingly, Ari et al. have recently demonstrated higher plasma nesfatin-1 levels in patients with MDD that is positively correlating with the Hamilton Depression Rating scale (Ari et al., 2011).

The possible involvement of CART and nesfatin- 1 in stressrelated human psychopathologies such as MDD has not been investigated. Therefore, in this study, we first studied the presence of CART and nesfatin/NUCB2 peptides in the post-mortem microdissected human EWcp and subsequently analyzed the dynamics of their mRNA expression in drug-free, depressed suicide victims, in comparison to non-depressed individuals, who died without any diagnosed neurodegenerative or psychiatric disorder (controls). Since women are twice as vulnerable to MDD as men (Gorman, 2006; Weissman et al., 1996), we investigated whether the results would be sex-specific.

\section{Material and methods}

Brains were obtained at autopsy from the Department of Forensic Medicine of Semmelweis University, Budapest, micro-dissected, and stored in the Human Brain Tissue Bank, Budapest. All subjects were males and females of Caucasian origin from Hungary (Budapest region), and post-mortem brain samples of these subjects were earlier used and described in detail in a previous study (Kozicz et al., 2008).

Briefly, exclusion criteria for subjects included the presence of prolonged agonal state or extended illness. Furthermore, since post-mortem delay can significantly alter gene expression profiles (Atz et al., 2007; Ervin et al., 2007; Vawter et al., 2006), subjects with a post-mortem delay longer than $12 \mathrm{~h}$ were also excluded from the present account. Brains from suicide victims with MDD ( 5 males and 3 females) and from controls ( 8 males and 8 females) were studied. Male subjects were matched for age and post-mortem delay (Table 1 ). The average age of male controls and suicide victims was $53.0 \pm 7.3$ and $40.0 \pm 8.7$ years, respectively. The average post-mortem delays were $2.7 \pm 1.6$ for male controls and $4.3 \pm 1.6 \mathrm{~h}$ for male suicide victims. No statistical difference was found between the average ages $(p=0.107)$ and postmortem delays $(p=0.092)$ of male controls and suicide victims. Female subjects were matched for post-mortem delay (Table 1 ). The average post-mortem delays were $4.3 \pm 1.6$ for female controls and $5.7 \pm 4.6 \mathrm{~h}$ for female suicide victims. No statistical difference was found for post-mortem delay between female controls and suicide victims $(p=0.97)$. The relatively low number of available samples of female suicide victims with a short pot-mortem delay $(<12 \mathrm{~h})$ in the Human Brain Tissue Bank, however, has compromised age-matching of female controls and suicide victims. Female controls (average age: $72.3 \pm 10.9)$ were significantly $(p=0.001)$ older then female suicide victims (average age: $42.0 \pm 0.0$ ). This apparent limitation in the study design will be addressed in detail in the discussion.

The medical, psychiatric and drug history of all suicide victims was obtained through chart review coupled with interviews with the attending physician(s)/ psychiatrist(s) and family members. Psychiatric evaluation for every suicide victim was made using psychological autopsies. Briefly, DSM-IV (Diagnostic and Statistical Manual of Mental Disorders, Fourth Edition) diagnoses were established by a panel of clinicians based on information obtained by means of proxy-based interviews complemented by medical and coroner records. Subjects included in this investigation consisted of suicides with MDD (non-bipolar depression) with recurrent episodes, who also died during an episode of major depression (Table 1). Suicide victims with a history of schizophrenia, epilepsy, or alcohol or other drug abuse were not included in the studies. Victims died by hanging ( 5 males and 2 females) or drug overdose (one female; there is no data about the drug used in her medical history). Some of the suicide victims had previously been treated for major depression, but

Table 1

Clinicopathological information and CART/NUCB2 expression values of suicide victims and control subjects.

\begin{tabular}{|c|c|c|c|c|c|c|c|c|}
\hline Sex & Age (years) & Body composition & Diagnosis & $\begin{array}{l}\text { Post-mortem } \\
\text { delay }(\mathrm{h})\end{array}$ & $\begin{array}{l}\text { Antidepressive } \\
\text { medication in the } \\
\text { last } 3 \text { months }\end{array}$ & Cause of death & $\begin{array}{l}\text { CART mRNA } \\
\text { expression in AU }\end{array}$ & $\begin{array}{l}\text { NUCB2 mRNA } \\
\text { expression in AU }\end{array}$ \\
\hline $\mathrm{M}$ & 51 & Average & Control & 5 & None & Cardiac arrest; arrhythmia & 0.43 & 2.88 \\
\hline M & 42 & Average & Control & 3,5 & None & Acute respiratory failure; cardiac ischemia & 0.03 & 1.99 \\
\hline M & 53 & Average & Control & 5 & None & Pulmonary embolism & 1.36 & 1.43 \\
\hline M & 55 & Below average & Control & 1 & None & Myocardial infarction & 7.80 & 1.28 \\
\hline M & 47 & Below average & Control & 2 & None & Acute cardiavascular failure; pulmonary embolism & 0.06 & 3.53 \\
\hline M & 63 & Average & Control & 2 & None & Acute cardiovascular failure & 0.24 & 1.71 \\
\hline M & 56 & Average & Control & 2 & None & Acute cardiovascular failure & 0.05 & 2.73 \\
\hline M & 47 & Average & Control & 2 & None & Acute cardiovascular failure; coronary ischemia & 0.03 & 4.01 \\
\hline $\mathrm{F}$ & 72 & Average & Control & 4,5 & None & Acute coronary ischemia & 0.62 & 16.8 \\
\hline $\mathrm{F}$ & 79 & Average & Control & 4,5 & None & Acute respiratory insufficiency & 0.26 & 0.83 \\
\hline $\mathrm{F}$ & 56 & Average & Control & 5 & None & Myocardial infarction & 0.02 & 1.15 \\
\hline $\mathrm{F}$ & 86 & Average & Control & 4,5 & None & Acute cardiovascular and respiratory insufficiency & 0.04 & 2.13 \\
\hline $\mathrm{F}$ & 56 & Average & Control & 5 & None & Myocardial infarction & 0.05 & 5.23 \\
\hline $\mathrm{F}$ & 79 & Average & Control & 4,5 & None & Acute cardiovascular and respiratory insufficiency & 0.04 & 1.4 \\
\hline $\mathrm{F}$ & 78 & Obese & Control & 1,5 & None & Pulmonary embolisms & 1.20 & 2.52 \\
\hline $\mathrm{F}$ & 72 & Average & Control & 3,5 & None & Myocardial infarction & 0.04 & 0.42 \\
\hline M & 52 & Average & MD/suicide & 2,5 & None & Hanging & 3.74 & 2.00 \\
\hline M & 31 & Average & $\mathrm{MD} /$ suicide & 6 & None & Hanging & 0.80 & 8.35 \\
\hline M & 43 & Average & MD/suicide & 3 & None & Hanging & 1.62 & 4.49 \\
\hline M & 42 & Average & MD/suicide & 4 & None & Hanging & 2.14 & 2.01 \\
\hline M & 32 & Below average & MD/suicide & 6 & None & Hanging & 0.22 & 4.16 \\
\hline $\mathrm{F}$ & 42 & Average & MD/suicide & 3 & None & Hanging & 3.59 & 1.35 \\
\hline $\mathrm{F}$ & 42 & Below average & $\mathrm{MD} /$ suicide & 3 & None & Hanging & 0.61 & 0.50 \\
\hline $\mathrm{F}$ & 42 & Average & MD/suicide & 11 & None & Hanging & 0.76 & 0.88 \\
\hline
\end{tabular}

Abbreviations: HBB-Human Brain Bank Budapest Hungary; M-male; F-female; MD-major depression; CSF-cerebrospinal fluid. 
details on the dose of medication or level of compliance with therapy could not reliably obtained in each case (Table 1). Nevertheless, psychological autopsy and medical records indicated that none of the persons included in the study had received antidepressant medication for at least 2 months before death. In addition, toxicological tests on blood samples did not reveal the presence of drugs or alcohol in cases of death by hanging (Table 1 ).

All controls died of a sudden death (Table 1). The causes of death were acute cardiac-respiratory failure or myocardial infarction. Psychological autopsy based on medical records confirmed the absence of psychiatric illness, antipsychotic medications and alcohol or drug abuse during the last 10 years. In addition, systematic neuropathological analysis (histopathology) did not show any neurodegenerative disorder for any person (Table 1). Harvesting of tissues was approved by the local ethics committee of Semmelweis University, and informed written consent had been obtained for use of brain material and clinical data from next of kin.

\subsection{Microdissection of the EWcp}

At the time of dissection, midbrains were sliced into $1 \mathrm{~mm}$ thick coronal sections, at 0 and $-10^{\circ} \mathrm{C}$. Under a stereomicroscope, samples from the rostral ventral portion of the midbrain, including the ventral central grey, oculomotor nuclei and Cajal nucleus, but dominated by the EWcp, were micro-dissected with a $1.5 \mathrm{~mm}$ micropunch needle (Ted Pella; Redding CA, USA). This approach allows minimal variations in the size and weight of the micro-dissected samples. Tissue samples from 3 consecutive sections were collected in Eppendorf tubes, and stored at $-70{ }^{\circ} \mathrm{C}$ until further use.

\subsection{Immunohistochemistry}

Midbrains including the EWcp of two male controls were micro-dissected and fixed by immersion in $4 \%$ paraformaldehyde, for $48 \mathrm{~h}$ at $4{ }^{\circ} \mathrm{C}$. Subsequently, serial $30 \mu \mathrm{m}$ thick coronal sections (perpendicular to the midbrain axis) were cut at the level of the superior colliculus on a freezing microtome (Microm GmBH, Walldorf, Germany).

Immunohistochemistry was performed according to our standard protocol (Kozicz et al., 2008). Briefly, after rinsing sections were treated with $0.5 \%$ Triton X-100 (Sigma-Aldrich, Zwijndrecht, The Netherlands), for $30 \mathrm{~min}$, to enhance antigen penetration. The they were incubated in a mixture of the following primary antisera in $2 \% \mathrm{NDS}$, for $48 \mathrm{~h}$ at $4{ }^{\circ} \mathrm{C}$ : (1) polyclonal (rabbit) anti-nesfatin-1 (human: $\mathrm{H}-003-97$; rat: H-003-22B; Phoenix Pharmaceutical, Inc.) at 1:1000, and (2) monoclonal (mouse) anti-CART (Ca6-1 F4D4, generous gift from Dr J.T. Clausen, Novo Nordisk A/S, Bagverd, Denmark) at 1:1500. The high specificity of these antisera has been described in detail before (anti-nesfatin: (Xu et al., 2009) and anti-CART: (Kozicz, 2003). Briefly, omitting the primary antisera, or preabsorbing them with excess of the respective immunogenic synthetic protein/peptide against which they had been raised (nesfatin-1; Cat No.: 003-22-A; Phoenix Pharmaceuticals; CART; gift from Dr J. T. Clausen, Novo Nordisc A/S, Bagverd, Denmark) fully abolished immunoreactivity. The secondary antisera (Jackson ImmunoResearch, Newmarket, Suffolk, UK) $\mathrm{Cy}^{2}$-conjugated antimouse IgG (1:100) and $\mathrm{Cy}^{3}$-conjugated anti-rabbit IgG (1:100) were applied for $3 \mathrm{~h}$. Following several rinses in PBS, sections were mounted on glass slides and incubated in $2 \%$ Sudan black, for $5 \mathrm{~min}$, to block non-specific background fluorescence.

Digital images were taken using a Leica confocal laser scanning microscope (Leica Microsystems TCS SP2 AOBS system; Leica).

\subsection{RNA extraction and CDNA synthesis}

The micropunched tissue samples were collected in $500 \mu$ lice-cold Trizol (Life Technologies, Paisley, UK). RNA was extracted with chloroform, precipitated with isopropyl alcohol, and dissolved in $30 \mu \mathrm{l}$ RNAse-free DEPC. Total RNA was measured
Table 2

Primer sequences.

\begin{tabular}{|c|c|c|c|}
\hline & Acc. number & Reverse; ‘5-...-3’ & Forward; ‘ $5-\ldots-3$ ’ \\
\hline hGAPDH & NM002046 & $\begin{array}{l}\text { ATGGCATGGACTGTG } \\
\text { GTCATG }\end{array}$ & ATCATCAGCAATGCCTCCTGC \\
\hline hCART & NM004291 & AGCGCTTCGATCAGCTCCT & CCGAGCCCTGGACATCTACTC \\
\hline hNUCB2 & NM005013 & $\begin{array}{l}\text { AGTTCATCCAGTCTC } \\
\text { GTCCTCAC }\end{array}$ & TGGAAACAGATCCGCATTTCA \\
\hline
\end{tabular}

with an Eppendorf Biophotometer (Vaudaux-Eppendorf AG, Basel, Switzerland). First-strand cDNA synthesis was performed using $1 \mu \mathrm{g}$ RNA dissolved in $11 \mu$ l RNAsefree DEPC containing $0.25 \mathrm{mU} \operatorname{pd}(\mathrm{N}) 6$ (random primers; Roche, Almere, The Netherlands), at $70{ }^{\circ} \mathrm{C}$ for $10 \mathrm{~min}$, followed by double-strand synthesis in $1 \times$ strand buffer (Life Technologies) with $10 \mathrm{mM}$ DTT, 20 U Rnasin (Promega, Madison, WI, USA), $0.5 \mathrm{mM}$ dNTPs (Roche) and $100 \mathrm{U}$ reverse transcriptase (Superscript II; Life Technologies), at $37^{\circ} \mathrm{C}$ for $75 \mathrm{~min}$ and at $95^{\circ} \mathrm{C}$ for $10 \mathrm{~min}$.

\subsection{Quantitative RT-PCR}

Quantitative RT-PCR was carried out according to our standard protocol (Derks et al., 2008; Kozicz et al., 2008), using, in brief, a total volume of $25 \mu \mathrm{l}$ buffer solution containing $5 \mu \mathrm{l}$ of template cDNA, $12.5 \mu \mathrm{l}$ SYBR Green Master mix (Applied Biosystems, Foster City, CA, USA), $1.5 \mu \mathrm{l}$ DEPC-treated MQ and $15 \mu \mathrm{M}$ of each primer. Primers for GAPDH, CART and NUCB2 were designed using Vector PrimerExpress software (Applied Biosystems) based on the respective rat cDNA sequences (for details see Table 2). Primer efficiencies (PE) were between 1.8 and 2.1 throughout all runs. Results of RT-PCR data were presented as threshold cycle $(\mathrm{Ct})$ values, with $\mathrm{Ct}$ defined as the $\mathrm{Ct}$ of RT-PCR at which the amplified product was first detected. Melting curve analysis showed a single component confirming the formation of a specific PCR product. All qRT-PCR reactions were carried out in triplicate. Data were analyzed using an equation in which average fold change in target gene expression equalled $\mathrm{PE}^{-\Delta \Delta \mathrm{Ct}}$. The $\Delta \Delta \mathrm{Ct}$ was calculated as average $\mathrm{Ct}$ of target minus average $\mathrm{Ct}$ of GAPDH. The resulting $\Delta \Delta \mathrm{Ct}$ values were then converted to a linear form by the $\mathrm{PE}^{-\Delta \Delta \mathrm{Ct}}$ method (Livak and Schmittgen, 2001).

\subsection{Statistical analysis}

The results are presented as mean \pm standard error of the mean (SEM). To compare the data between experiment groups, two-way analysis of variance (ANOVA; StatSoft, Tulsa OK, USA) with "victim status" and "gender" as independent variables was performed. As data were not normally distributed, log-transformation of data were performed on the basis of tests for normality (Shapiro and Wilk, 1965) and for homogeneity of variance (Bartlett's Chi-square test; (Snedecor and Cochran, 1989). Post-hoc analyses were carried out with Scheffe's test (Hsu, 1996) using Statistica (StatSoft). Pearson's R correlation test (StatSoft) was used to compare CART and nesfatin/NUCB2 mRNA expression levels with the age, post-mortem time and body composition of controls. In all cases alpha was $5 \%$.

\section{Results}

\subsection{Colocalization}

Both CART-ir and nesfatin-1-ir was abundant in the human EWcp, and colocalized in EWcp neurons (Fig. 1A-D).
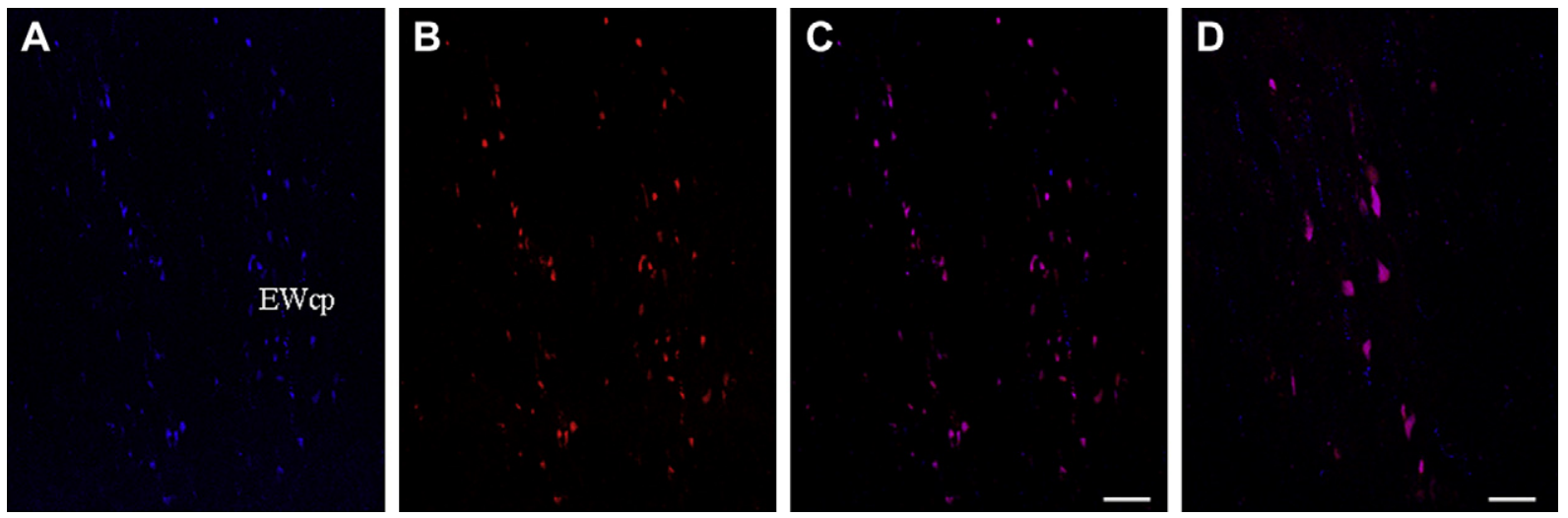

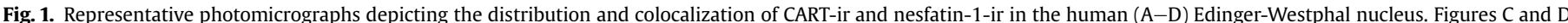

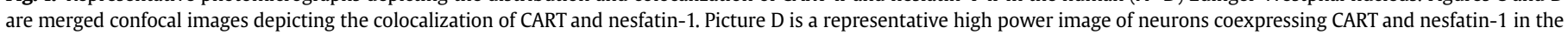
human midbrain. Scale bars; A-C: $200 \mu \mathrm{m}$ and D: $50 \mu \mathrm{m}$. EWcp-Edinger-Westphal nucleus. 


\section{2. $q R T-P C R$ analysis of human depressed suicide victims}

CART and nesfatin/NUCB2 mRNAs were detected in microdissected rostro-ventral midbrain samples containing the EWcp of both controls and suicide victims. Two-way ANOVA revealed a clear effect of "victim status" $\left(F_{1,24}=4.38 ; p<0.05\right)$. Post-hoc analysis showed a significant $(p<0.05) 3.8$ times increase of CART mRNA in age-matched male suicide victims vs. controls. CART mRNA expression was 5.9 times higher $(p<0.005)$ in female suicide victims $v$ s. controls (Table 1 and Fig. $2 \mathrm{~A}$ ).

Next, we analyzed the nesfatin/NUCB2 mRNA contents of the EWcp (Table 1 and Fig. 2B). Two-way ANOVA revealed a significant effect of 'sex' $\left(F_{1,24}=8.23, p<0.01\right)$ and 'victim status by sex' interaction $\left(F_{1,24}=4.45, p<0.05\right)$. In males, nesfatin/NUCB2 mRNA content was 1.8 times higher in drug-free depressed suicide victims $v s$. controls $(p<0.05)$. In female suicide victims, however, this content was 2.7 times lower than that in controls $(p<0.05)$.

Since female suicide victims were younger than their female controls, we tested for a possible effect of age on CART and nesfatin/ NUCB2 mRNA expression. Pearson R correlation test revealed no correlation between 'age' and CART mRNA or nesfatin/NUCB2 mRNA contents neither in male $(r=0.43 ; p>0.05)$ nor in female $(r=0.68 ; p>0.05)$ controls. We also analyzed the effect of age on CART and nesfatin/NUCB2 mRNA expression including all subjects. We found no correlation between age and CART $(r=0.26 ; p>0.05)$ or age and nesfatin/NUCB2 $(r=0.17 ; p>0.05)$ mRNA abundance.

Also the CART and nesfatin/NUCB2 mRNA contents of the only female suicide victim with a drug-overdose were in the range of the means of the two females that committed suicide by hanging.
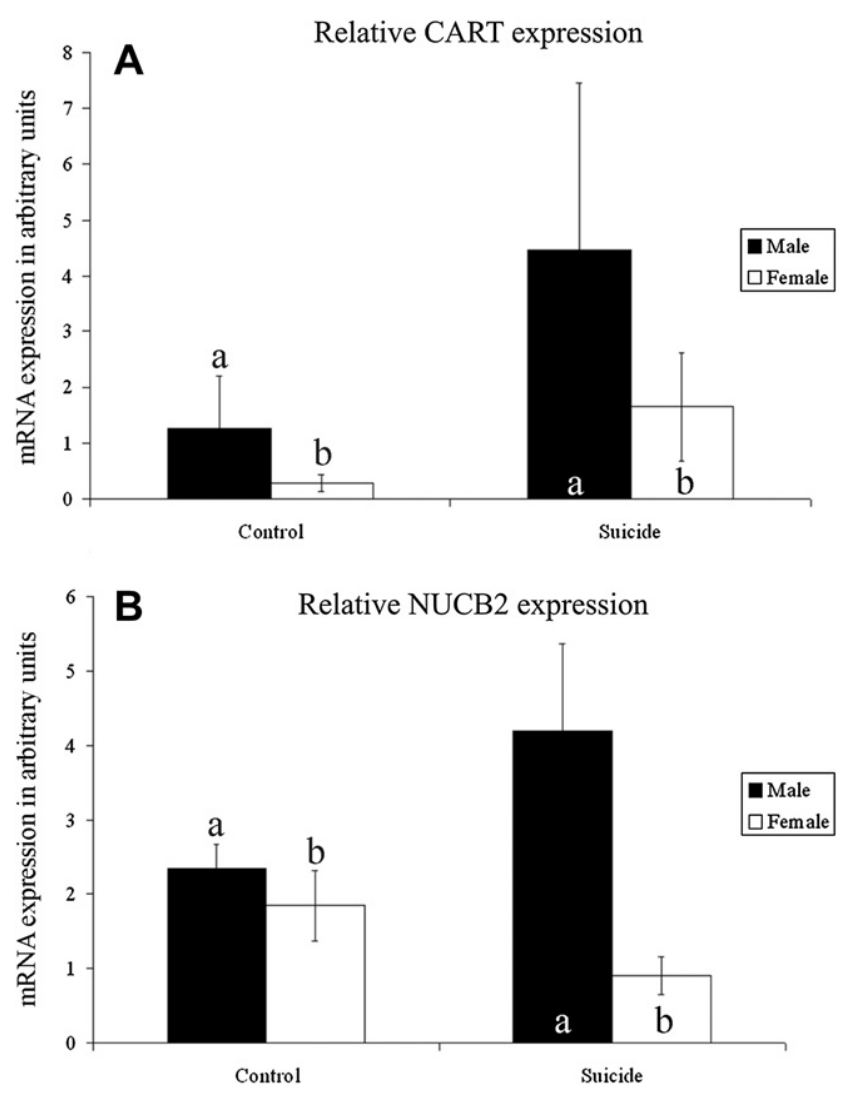

Fig. 2. Relative CART (A) and NUCB2 (B) mRNA expression in the EWcp of male controls and drug-free depressed suicide victims, expressed as $\Delta \Delta \mathrm{Ct}$ values. The letters in the bars represent experimental groups and the letter over the bars indicate the experimental group with which significant difference exists (Scheffe's post hoc test; $p<0.05)$. Error bars represent standard error of means.
Statistical analysis of GAPDH mRNA expression did not reveal any significant difference $(p>0.05)$ among groups, supporting the suitability of GAPDH mRNA to normalize the PCR-data.

\section{Discussion}

In this study, we have analyzed CART and nesfatin/NUCB2 contents of post mortem samples of rostro-ventral midbrains containing the Edinger-Westphal nucleus of drug-free, depressed suicide victims of both sexes. The results extend prior observations on the possible involvement of CART and nesfatin/NUCB2 in MDD in humans (Ari et al., 2011; Miraglia del Giudice et al., 2006) and in anxiety- and depressive-like behaviour in rodents (Dandekar et al., 2008; Garcia-Galiano et al., 2010; Merali et al., 2008; Wiehager et al., 2009) in a number of ways. Firstly, we showed that CART and nesfatin-1 were present and colocalized in EWcp neurons. Secondly, we found that compared to controls, CART mRNA expression was increased in male (nearly 4 times) and female (nearly 6 times) suicide victims. Thirdly, nesfatin/NUCB2 mRNA expression was higher in male (nearly 2 times), but lower (nearly 3 times) in female suicide victims than in corresponding controls.

Although the sample size utilized is admittedly small following control for sample quality, we note that it was large enough to detect consistent changes in CART and nesfatin/NUCB2 mRNA. A further limitation is the analysis of only three female suicide victims who were significantly younger then female controls. In theory, CART and nesfatin/NUCB2 mRNA expressions might be influenced by age. To date no experimental evidence is available to support an effect of age on CART and nesfatin/NUCB2 mRNA expressions. In fact, in the present study no correlation between age and CART and nesfatin/NUCB2 mRNA expression was found, making a biasing influence of age on our data unlikely. Age could also have an effect on reproductive hormone levels which in turn could also influence the mRNA expression of CART and nesfatin/ NUCB2 in females. Unfortunately, no human studies are available comparing CART and nesfatin/NUCB2 expression before and after menopause. However, the magnitude of changes observed in this study compared to changes in some brain substances in relation to reproductive hormone levels are far bigger (Singh et al., 1995; Zhou et al., 2005) suggesting that possible differences in reproductive hormone levels alone cannot be accounted for the observed differences, however this possibility has to be tested future studies.

While this study documents significant changes in the expression of CART and nesfatin/NUCB2, it remains possible that factors other than a history of MDD, including e.g. agonal state and suicidality, contribute to the findings. As to agonal state, gene expression profiles in the post mortem brain are influenced by asphyxia/ ischemia during agony (e.g. Atz et al., 2007; Ervin et al., 2007; Vawter et al., 2006). Recently, Li et al. (2004) found that individuals who suffered prolonged agonal states exhibited a consistent change in expression of various genes, whereas those who experienced brief deaths caused by accidents, acute cardio-respiratory events or asphyxia, generally did not (Li et al., 2004). Since in our study samples were used of individuals with a brief death (hanging), we believe that asphyxia cannot explain the differences found in gene expression between groups, although it may have randomly increased the variability of individual data.

With respect to suicidality, suicidal behaviour may be a unique entity, reflecting the summations of various mechanisms in the brain (van Heeringen, 2001), each of which may differ across individuals, and may not reflect those that govern major depression itself. While it might be considered that midbrain CART and nesfatin/NUCB2 dysregulation witnessed in this study indicates an effect of suicidal behaviour rather than depression on pathobiology, we feel that this is unlikely, because a similar increase in CART 
peptide in the midbrain periaqueductal grey was seen in genetic rat models of depression (FSL rats; Wiehager et al., 2009), and an association between depression and a point mutation in the CART gene has been found in an Italian family (Miraglia del Giudice et al., 2006).

Central injection of CART and nesfatin/NUCB2 into male rodents increases anxiety (Koylu et al., 2006; Merali et al., 2008). This is in line with our observation of increased CART and nesfatin/NUCB2 mRNA expressions in depressed suicide victims. The decreased mRNA level of nesfatin/NUCB2 in females, however, suggest that nesfatin/NUCB2 may have a sex-specific effect on anxiety, c.q. anxiolysis. Although this would be plausible scenario, the finding that plasma nesfatin-1 levels were elevated in both male and female patients with MDD would argue against a sex-specific involvement of nesfatin-1 in influencing mood (Ari et al., 2011). Nonetheless, This issue has to be addressed and clarified in future studies.

Mutations in the human CART gene have been associated with depression (Miraglia del Giudice et al., 2006), and increased CART immunoreactivity is found in the midbrain periaqueductal grey and in the hypothalamus of FSL rats that show increased depressionlike behaviour (Wiehager et al., 2009). The notion that CART may play a role in the pathogenesis of major depression is further corroborated by the fact that it can modulate signal transduction pathways of neurotrophic factors such as brain-derived neurotrophic factor, and directly control the expression of genes coding for key enzymes in the biosynthesis of serotonin, factors all assumed to be involved in depression (for reviews see: Ma et al., 2007; Pae et al., 2007; Rogge et al., 2008). More specifically, CART markedly enhances hypothalamic and cortical serotonin release in the rat (Vaarmann and Kask, 2001), but the neuronal circuitry underpinning this phenomenon is not fully understood. One possible mechanism could be via CART in the midbrain EWcp nucleus. More specifically, functional projections of EWcp neurons to the dorsal raphe nucleus have been identified in the rat (Bachtell et al., 2004; Kozicz, 2010; Turek and Ryabinin, 2005). Therefore, EWcp CART neurons could control the activity of serotoninergic neurons in the dorsal raphe nucleus by releasing CART, thereby modulating the activity of these neurons, and consequently the serotonin tone in limbic forebrain structures. The question if nesfatin/NUCB2 could also play a role in controlling/modulating the brain's monoaminergic system remains at future issue.

MDD is associated with various symptoms (e.g. anhedonia, appetite dysregulation), which may result from impairments of affected brain regions and disturbed neuropeptide dynamics. As follow we will discuss several lines of (correlative) evidence supporting the possible involvement of EWcp CART and nesfatin/ NUCB2 in the pathobiology of these symptoms.

An increasing body of evidence shows that drugs producing hedonic effects (e.g. alcohol, methylphenidate, cocaine and methamphetamine) consistently lead to increased neuronal activity of EWcp in rodents (Ryabinin and Weitemier, 2006; Spangler et al., 2009; Trinh et al., 2003). In addition, studies with alcohol confirmed that EWcp is not only involved in mediating effects of drugs, but also in their addictive potential (Bachtell et al., 2002, 2003). There is substantial evidence connecting CART with reward circuitries in the mammalian brain (for review see e.g.: Rogge et al., 2008; Shirayama and Chaki, 2006). More specifically, in a Korean population, association was found between a polymorphism in intron 1 of the CART gene and alcoholism (Jung et al., 2004), and CART-peptide containing neurons are activated by acute administration of psychostimulants (Rogge et al., 2008; Shirayama and Chaki, 2006).

Sex-specificity has been consistently found in stress adaptation and stress-induced brain diseases (Afifi, 2007; Kessler et al., 2003).
Interestingly, depression is twice as common among women than men (Gorman, 2006; Weissman et al., 1996), and females reveal two- to three-fold higher rates of suicide attempts (Weissman et al., 1999). Although the samples size utilized in the present study is admittedly small, we note that this was sufficiently large to demonstrate statistically significant, strong differences in CART and nesfatin/NUCB2 mRNA expression between the experimental groups. Therefore, our study suggests -notwithstanding the above mentioned limitations in our study design- a sex difference in CART and nesfatin/NUCB2 mRNA expressions in the EWcp of depressed suicide victims, which may contribute to the sex-specific pathobiology of MDD. Interestingly, male suicide victims showed higher nesfatin/NUCB2 mRNA expression than controls whereas in female suicides this mRNA was lower than in the control persons. Two recent studies supported the hypothesized association between obesity and depression outcomes for women but not men (Atlantis and Baker, 2008; Needham and Crosnoe, 2005). Since central nesfatin-1 is clearly associated with feeding (Kohno et al., 2008; Oh et al., 2006) our demonstration of a possible sex-specific dysregulation of nesfatin/NUCB2 mRNA in the EWcp in suicide victims suggests that nesfatin/NUCB2 in the human EWcp may play a sexspecific role in e.g. the dysregulation of appetite in MDD. Such a mechanisms for central action for nesfatin/NUCB2 could be further supported by the fact that stress, a major trigger inducing appetite, affects nesfatin- 1 neurons in several brain nuclei, including the EWcp (Goebel-Stengel et al., 2011; Stengel et al., 2009; Xu et al., 2010; Yoshida et al., 2010). In contrast, alterations in food intake (2-days fasting) do not effect nesfatin/NUCB2 expression in EWcp (Okere et al., 2010; Xu et al., 2009, 2010). Taken together, these data strongly suggest that nesfatin/NUCB2 in the EWcp is primarily involved in the stress response, and its influence on appetite regulation could be secondary induced by stress.

In conclusion, we have found a difference in the expression of CART and nesfatin/NUCB2 in the midbrain of depressed suicide victims vs. controls that may imply a role for EWcp CART and nesfatin/NUCB2 in the aetiology major depression c.q. suicidality. Our data also resonate with recent interest in examining interactions between traditional mood substrates and pathways involved in the control of food intake and metabolism (for reviews see e.g.: Gomez-Pinilla, 2008; Krishnan and Nestler, 2008). There could be several candidate brain centres within which complex interactions between peripheral metabolic signals and centrally released regulators of feeding and arousal could underpin the general theme that an animal's metabolic status greatly influences mood and motivation. We propose that one of these centres could be the recently identified population of midbrain centrally projecting neurons in the Edinger-Westphal nucleus.

\section{Acknowledgments}

The authors thank Debbie Tilburg-Ouwens for excellent technical assistance. This work was supported by the Netherlands Organization for Scientific Research NWO (\#864.05.008; T.K.) and EU Grant FP6 (BNEII No LSHM-CT-204-503039; M.P.).

\section{References}

Afifi, M., 2007. Gender differences in mental health. Singapore Med. J. 48, 385-391. Ari, M., Ozturk, O.H., Bez, Y., Oktar, S., Erduran, D., 2011. High plasma nesfatin-1 level in patients with major depressive disorder. Prog. Neuropsychopharmacol. Biol. Psychiatry 35 (2), 497-500.

Atlantis, E., Baker, M., 2008. Obesity effects on depression: systematic review of epidemiological studies. Int. J. Obes. (Lond) 32, 881-891.

Atz, M., Walsh, D., Cartagena, P., Li, J., Evans, S., Choudary, P., Overman, K., Stein, R., Tomita, H., Potkin, S., Myers, R., Watson, S.J., Jones, E.G., Akil, H., Bunney Jr., W.E., Vawter, M.P., 2007. Methodological considerations for gene expression profiling of human brain. J. Neurosci. Methods 163, 295-309. 
Bachtell, R.K., Tsivkovskaia, N.O., Ryabinin, A.E., 2002. Strain differences in urocortin expression in the Edinger-Westphal nucleus and its relation to alcohol-induced hypothermia. Neuroscience 113, 421-434.

Bachtell, R.K., Weitemier, A.Z., Galvan-Rosas, A., Tsivkovskaia, N.O., Risinger, F.O., Phillips, T.J., Grahame, N.J., Ryabinin, A.E., 2003. The Edinger-Westphal-lateral septum urocortin pathway and its relationship to alcohol consumption. J. Neurosci. 23, 2477-2487.

Bachtell, R.K., Weitemier, A.Z., Ryabinin, A.E., 2004. Lesions of the Edinger-Westphal nucleus in C57BL/6J mice disrupt ethanol-induced hypothermia and ethanol consumption. Eur. J. Neurosci. 20, 1613-1623.

Becker, C., Zeau, B., Rivat, C., Blugeot, A., Hamon, M., Benoliel, J.J., 2008. Repeated social defeat-induced depression-like behavioral and biological alterations in rats: involvement of cholecystokinin. Mol. Psychiatry 13, 1079-1092.

Brailoiu, G.C., Dun, S.L., Brailoiu, E., Inan, S., Yang, J., Chang, J.K., Dun, N.J., 2007. Nesfatin-1: distribution and interaction with a $G$ protein-coupled receptor in the rat brain. Endocrinology 148, 5088-5094.

Couceyro, P.R., Koylu, E.O., Kuhar, M.J., 1997. Further studies on the anatomical distribution of CART by in situ hybridization. J. Chem. Neuroanat. 12, 229-241.

Dandekar, M.P., Singru, P.S., Kokare, D.M., Subhedar, N.K., 2008. Cocaine- and amphetamine-regulated transcript peptide plays a role in the manifestation of depression: social isolation and olfactory bulbectomy models reveal unifying principles. Neuropsychopharmacology 34, 1288-1300.

Derks, N.M., Muller, M., Gaszner, B., Tilburg-Ouwens, D.T., Roubos, E.W., Kozicz, L.T., 2008. Housekeeping genes revisited: different expressions depending on gender, brain area and stressor. Neuroscience 156, 305-309.

Douglass, J., McKinzie, A.A., Couceyro, P., 1995. PCR differential display identifies a rat brain mRNA that is transcriptionally regulated by cocaine and amphetamine. J. Neurosci. 15, 2471-2481.

Eaton, K., Sallee, F.R., Sah, R., 2007. Relevance of neuropeptide Y (NPY) in psychiatry. Curr. Top. Med. Chem. 7, 1645-1659.

Edinger, 1885. Über den Verlauf der centralen Hirnnervenbahnen mit Demonstrationen von Präparaten. Arch. Psychiat Nervenkr 16, 858-859.

Ervin, J.F., Heinzen, E.L., Cronin, K.D., Goldstein, D., Szymanski, M.H., Burke, J.R., Welsh-Bohmer, K.A., Hulette, C.M., 2007. Postmortem delay has minimal effect on brain RNA integrity. J. Neuropathol. Exp. Neurol. 66, 1093-1099.

Foo, K.S., Brismar, H., Broberger, C., 2008. Distribution and neuropeptide coexistence of nucleobindin-2 mRNA/nesfatin-like immunoreactivity in the rat CNS. Neuroscience 156, 563-579.

Garcia-Galiano, D., Navarro, V.M., Gaytan, F., Tena-Sempere, M., 2010. Expanding roles of NUCB2/nesfatin-1 in neuroendocrine regulation. J. Mol. Endocrinol. 45 (5), 281-290.

Georgescu, D., Sears, R.M., Hommel, J.D., Barrot, M., Bolanos, C.A., Marsh, D.J., Bednarek, M.A., Bibb, J.A., Maratos-Flier, E., Nestler, E.J., DiLeone, R.J., 2005. The hypothalamic neuropeptide melanin-concentrating hormone acts in the nucleus accumbens to modulate feeding behavior and forced-swim performance. J. Neurosci. 25, 2933-2940.

Goebel-Stengel, M., Wang, L., Stengel, A., Tache, Y., 2011. Localization of nesfatin-1 neurons in the mouse brain and functional implication. Brain Res. 1396, 20-34.

Gomez-Pinilla, F., 2008. Brain foods: the effects of nutrients on brain function. Nat. Rev. Neurosci. 9, 568-578.

Gorman, J.M., 2006. Gender differences in depression and response to psychotropic medication. Gend. Med. 3, 93-109.

Gysling, K., Forray, M.I., Haeger, P., Daza, C., Rojas, R., 2004. Corticotropin-releasing hormone and urocortin: redundant or distinctive functions? Brain Res. Brain Res. Rev. 47, 116-125.

Heilig, M., 2004. The NPY system in stress, anxiety and depression. Neuropeptides $38,213-224$.

Hsu, J.C., 1996. Multiple Comparisons; Theory And Methods. Chapman \& Hall CRC Boca Raton, Florida, USA.

Jung, S.K., Hong, M.S., Suh, G.J., Jin, S.Y., Lee, H.J., Kim, B.S., Lim, Y.J., Kim, M.K., Park, H.K., Chung, J.H., Yim, S.V., 2004. Association between polymorphism in intron 1 of cocaine- and amphetamine-regulated transcript gene with alcoholism, but not with bipolar disorder and schizophrenia in Korean population. Neurosci. Lett. 365, 54-57.

Kessler, R.C., Berglund, P., Demler, O., Jin, R., Koretz, D., Merikangas, K.R., Rush, A.J., Walters, E.E., Wang, P.S., 2003. The epidemiology of major depressive disorder: results from the National Comorbidity Survey Replication (NCS-R). JAMA 289, 3095-3105.

Kohno, D., Nakata, M., Maejima, Y., Shimizu, H., Sedbazar, U., Yoshida, N., Dezaki, K. Onaka, T., Mori, M., Yada, T., 2008. Nesfatin-1 neurons in paraventricular and supraoptic nuclei of the rat hypothalamus coexpress oxytocin and vasopressin and are activated by refeeding. Endocrinology 149, 1295-1301.

Koylu, E.O., Balkan, B., Kuhar, M.J., Pogun, S., 2006. Cocaine and amphetamine regulated transcript (CART) and the stress response. Peptides 27, 1956-1969.

Koylu, E.O., Couceyro, P.R., Lambert, P.D., Kuhar, M.J., 1998. Cocaine- and amphetamine-regulated transcript peptide immunohistochemical localization in the rat brain. J. Comp. Neurol. 391, 115-132.

Kozicz, T., 2003. Neurons colocalizing urocortin and cocaine and amphetamineregulated transcript immunoreactivities are induced by acute lipopolysaccharide stress in the Edinger-Westphal nucleus in the rat. Neuroscience 116, 315-320.

Kozicz, T., 2007. On the role of urocortin 1 in the non-preganglionic EdingerWestphal nucleus in stress adaptation. Gen. Comp. Endocrinol. 153, 235-240.

Kozicz, T., 2010. The missing link; the significance of urocortin 1/urocortin 2 in the modulation of the dorsal raphe serotoninergic system. Mol. Psychiatry 15, 340-341.
Kozicz, T., Bittencourt, J.C., May, P.J., Reiner, A., Gamlin, P.D., Palkovits, M., Horn, A.K. Toledo, C.A., Ryabinin, A.E., 2011a. The Edinger-Westphal nucleus: a historical, structural, and functional perspective on a dichotomous terminology. J. Comp. Neurol. 519 (8), 1413-1434

Kozicz, T., Sterrenburg, L., Xu, L., 2011b. Does midbrain urocortin 1 matter? A 15year journey from stress (mal)adaptation to energy metabolism. Stress.

Kozicz, T., Tilburg-Ouwens, D., Faludi, G., Palkovits, M., Roubos, E., 2008. Gender-related urocortin 1 and brain-derived neurotrophic factor expression in the adult human midbrain of suicide victims with major depression. Neuroscience 152,1015-1023.

Kozicz, T., Yanaihara, H., Arimura, A., 1998. Distribution of urocortin-like immunoreactivity in the central nervous system of the rat. J. Comp. Neurol. 391, 1-10.

Krishnan, V., Nestler, E.J., 2008. The molecular neurobiology of depression. Nature 455, 894-902.

Kuperman, Y., Issler, O., Regev, L., Musseri, I., Navon, I., Neufeld-Cohen, A., Gil, S Chen, A., 2010. Perifornical Urocortin-3 mediates the link between stress-induced anxiety and energy homeostasis. Proc. Natl. Acad. Sci. U. S. A 107 (18), 8393-8398.

Li, J.Z., Vawter, M.P., Walsh, D.M., Tomita, H., Evans, S.J., Choudary, P.V., Lopez, J.F Avelar, A., Shokoohi, V., Chung, T., Mesarwi, O., Jones, E.G., Watson, S.J., Akil, H. Bunney Jr., W.E., Myers, R.M., 2004. Systematic changes in gene expression in postmortem human brains associated with tissue $\mathrm{pH}$ and terminal medical conditions. Hum. Mol. Genet. 13, 609-616.

Livak, K.J., Schmittgen, T.D., 2001. Analysis of relative gene expression data using real-time quantitative PCR and the 2(-Delta Delta C(T)) Method. Methods 25 (4), 402-408.

Lu, X.Y., 2007. The leptin hypothesis of depression: a potential link between mood disorders and obesity? Curr. Opin. Pharmacol. 7 (6), 648-652.

Lutter, M., Sakata, I., Osborne-Lawrence, S., Rovinsky, S.A., Anderson, J.G., Jung, S. Birnbaum, S., Yanagisawa, M., Elmquist, J.K., Nestler, E.J., Zigman, J.M., 2008. The orexigenic hormone ghrelin defends against depressive symptoms of chronic stress. Nat. Neurosci. 11, 752-753.

Ma, Z., Pearson, E., Tao, R., 2007. CART peptides increase 5-hydroxytryptamine in the dorsal raphe and nucleus accumbens of freely behaving rats. Neurosci. Lett. 417, 303-307.

McBriar, M.D., 2006. Recent advances in the discovery of melanin-concentrating hormone receptor antagonists. Curr. Opin. Drug Discov. Devel 9, 496-508.

Merali, Z., Cayer, C., Kent, P., Anisman, H., 2008. Nesfatin-1 increases anxiety- and fear-related behaviors in the rat. Psychopharmacology (Berl) 201, 115-123.

Miraglia del Giudice, E., Santoro, N., Fiumani, P., Dominguez, G., Kuhar, M.J., Perrone, L., 2006. Adolescents carrying a missense mutation in the CART gene exhibit increased anxiety and depression. Depress. Anxiety 23, 90-92.

Needham, B.L., Crosnoe, R., 2005. Overweight status and depressive symptoms during adolescence. J. Adolesc. Health 36, 48-55.

Oh, I., Shimizu, H., Satoh, T., Okada, S., Adachi, S., Inoue, K., Eguchi, H. Yamamoto, M., Imaki, T., Hashimoto, K., Tsuchiya, T., Monden, T., Horiguchi, K. Yamada, M., Mori, M., 2006. Identification of nesfatin-1 as a satiety molecule in the hypothalamus. Nature 443, 709-712.

Okere, B., Xu, L., Roubos, E.W., Sonetti, D., Kozicz, T., 2010. Restraint stress alters the secretory activity of neurons co-expressing urocortin-1, cocaine- and amphetamine-regulated transcript peptide and nesfatin- 1 in the mouse Edinger-Westphal nucleus. Brain Res.

Orsetti, M., Di Brisco, F., Canonico, P.L., Genazzani, A.A., Ghi, P., 2008. Gene regulation in the frontal cortex of rats exposed to the chronic mild stress paradigm, an animal model of human depression. Eur. J. Neurosci. 27, 2156-2164.

Pae, C.U., Lee, C., Paik, I.H., 2007. Therapeutic implication of cocaine- and amphetamine-regulated transcript (CART) in the treatment of depression. Med. Hypotheses 69, 132-135.

Pan, W., Kastin, A.J., 2008. Urocortin and the brain. Prog. Neurobiol. 84, 148-156.

Rogge, G., Jones, D., Hubert, G.W., Lin, Y., Kuhar, M.J., 2008. CART peptides: regulators of body weight, reward and other functions. Nat. Rev. Neurosci. 9, 747-758.

Ryabinin, A.E., Weitemier, A.Z., 2006. The urocortin 1 neurocircuit: ethanol-sensitivity and potential involvement in alcohol consumption. Brain Res. Rev. 52, 368-380.

Shao, L., Martin, M.V., Watson, S.J., Schatzberg, A., Akil, H., Myers, R.M., Jones, E.G. Bunney, W.E., Vawter, M.P., 2008. Mitochondrial involvement in psychiatric disorders. Ann. Med. 40, 281-295.

Shapiro, S.S., Wilk, M.B., 1965. An analysis of variance test for normality. Biometrika 52, 591-599.

Shirayama, Y., Chaki, S., 2006. Neurochemistry of the nucleus accumbens and its relevance to depression and antidepressant action in rodents. Curr. Neuropharmacol 4, 277-291.

Singh, M., Meyer, E.M., Simpkins, J.W., 1995. The effect of ovariectomy and estradio replacement on brain-derived neurotrophic factor messenger ribonucleic acid expression in cortical and hippocampal brain regions of female Sprague-Dawley rats. Endocrinology 136, 2320-2324.

Skelton, K.H., Owens, M.J., Nemeroff, C.B., 2000. The neurobiology of urocortin Regul. Pept. 93, 85-92.

Snedecor, G.W., Cochran, W.G., 1989. Statistical Methods. Iowa State University Press, Ames, IA, USA

Spangler, E., Cote, D.M., Anacker, A.M., Mark, G.P., Ryabinin, A.E., 2009. Differential sensitivity of the perioculomotor urocortin-containing neurons to ethanol, psychostimulants and stress in mice and rats. Neuroscience 160,115-125.

Stengel, A., Goebel, M., Wang, L., Tache, Y., 2009. Abdominal surgery activates nesfatin-1 immunoreactive brain nuclei in rats. Peptides.

Trinh, J.V., Nehrenberg, D.L., Jacobsen, J.P., Caron, M.G., Wetsel, W.C., 2003. Differential psychostimulant-induced activation of neural circuits in dopamine transporter knockout and wild type mice. Neuroscience 118, 297-310. 
Turek, V.F., Ryabinin, A.E., 2005. Ethanol versus lipopolysaccharide-induced hypothermia: involvement of urocortin. Neuroscience 133, 1021-1028.

Vaarmann, A., Kask, A., 2001. Cocaine and amphetamine-regulated transcript peptide (CART(62-76))-induced changes in regional monoamine levels in ratbrain. Neuropeptides 35, 292-296.

van Heeringen, C., 2001. Suicide, serotonin, and the brain. Crisis 22, 66-70.

Vaughan, J., Donaldson, C., Bittencourt, J., Perrin, M.H., Lewis, K., Sutton, S., Chan, R., Turnbull, A.V., Lovejoy, D., Rivier, C., 1995. Urocortin, a mammalian neuropeptide related to fish urotensin I and to corticotropin-releasing factor. Nature 378, 287-292.

Vawter, M.P., Tomita, H., Meng, F., Bolstad, B., Li, J., Evans, S., Choudary, P., Atz, M., Shao, L., Neal, C., Walsh, D.M., Burmeister, M., Speed, T., Myers, R., Jones, E.G. Watson, S.J., Akil, H., Bunney, W.E., 2006. Mitochondrial-related gene expression changes are sensitive to agonal-pH state: implications for brain disorders. Mol. Psychiatry 11 (615), 663-679.

Weissman, M.M., Bland, R.C., Canino, G.J., Faravelli, C., Greenwald, S., Hwu, H.G Joyce, P.R., Karam, E.G., Lee, C.K., Lellouch, J., Lepine, J.P., Newman, S.C., RubioStipec, M., Wells, J.E., Wickramaratne, P.J., Wittchen, H., Yeh, E.K., 1996. Crossnational epidemiology of major depression and bipolar disorder. JAMA 276 293-299.

Weissman, M.M., Bland, R.C., Canino, G.J., Greenwald, S., Hwu, H.G., Joyce, P.R., Karam, E.G., Lee, C.K., Lellouch, J., Lepine, J.P., Newman, S.C., Rubio-Stipec, M., Wells, J.E., Wickramaratne, P.J., Wittchen, H.U., Yeh, E.K., 1999. Prevalence of suicide ideation and suicide attempts in nine countries. Psychol. Med. 29, 9-17.

Westphal, C., 1887. Über einen fall von chronischer progressiver Lähmung der Augenmuskeln (Ophtalmoplegia externa) nebst Beschreibung von
Ganglienzellengruppen im Bereiche des Ocolumotoriuskerns. Arch. Psychiat Nervenkr 98, 846-871.

Wiehager, S., Beiderbeck, D.I., Gruber, S.H., El Khoury, A., Wamsteeker, J. Neumann, I.D., Petersen, A., Mathe, A.A., 2009. Increased levels of cocaine and amphetamine regulated transcript in two animal models of depression and anxiety. Neurobiol. Dis. 34, 375-380.

Xu, L., Bloem, B., Gaszner, B., Roubos, E., Kozicz, T., 2010. Stress-related changes in the activity of cocaine- and amphetamine-regulated transcript and nesfatin neurons in the midbrain non-preganglionic Edinger-Westphal nucleus in the rat. Neuroscience.

Xu, L., Bloem, B., Gaszner, B., Roubos, E.W., Kozicz, T., 2009. Sex-specific effects of fasting on urocortin 1, cocaine- and amphetamine-regulated transcript peptide and nesfatin-1 expression in the rat Edinger-Westphal nucleus. Neuroscience $162,1141-1149$.

Yamada, N., Katsuura, G., Ochi, Y., Ebihara, K., Kusakabe, T., Hosoda, K., Nakao, K., 2011. Impaired CNS leptin action is implicated in depression associated with obesity. Endocrinology.

Yoshida, N., Maejima, Y., Sedbazar, U., Ando, A., Kurita, H., Damdindorj, B., Takano, E., Gantulga, D., Iwasaki, Y., Kurashina, T., Onaka, T., Dezaki, K., Nakata, M., Mori, M., Yada, T., 2010. Stressor-responsive central nesfatin-1 activates corticotropin-releasing hormone, noradrenaline and serotonin neurons and evokes hypothalamic-pituitary-adrenal axis. Aging (Albany. NY) 2 (11), 775-784

Zhou, J., Zhang, H., Cohen, R.S., Pandey, S.C., 2005. Effects of estrogen treatment on expression of brain-derived neurotrophic factor and cAMP response elementbinding protein expression and phosphorylation in rat amygdaloid and hippocampal structures. Neuroendocrinology 81, 294-310. 